\title{
EFEKTIVITAS PENGGUNAAN MEDIA PEMBELAJARAN BERBASIS VIDEO TERHADAP PEMAHAMAN KONSEP MATEMATIS SISWA
}

\author{
Yesi Gusmania*, Tri Wulandari \\ Program Studi Pendidikan Matematika, Fakultas Keguruan dan Ilmu Pendidikan \\ Universitas Riau Kepulauan, Batam, Kepulauan Riau, Indonesia \\ e-mail: yesigusmania18@gmail.com
}

\begin{abstract}
Abstrak. Penelitian ini bertujuan untuk mengetahui perbedaan efektivitas dalam penggunaan media pembelajaran berbasis video dengan pembelajaran konvensional terhadap pemahaman konsep matematis siswa. Jenis penelitian ini adalah eksperimen semu dengan desain penelitian PretestPosttest Control Group Design. Populasi penelitian ini adalah seluruh siswa SMPN 20 Batam kelas VIII tahun pelajaran 2016/2017. Pengambilan sampel dilakukan dengan teknik Cluster Random Sampling. Sampel penelitian kelas eksperimen VIII.4 dan sampel kelas kontrol VIII.2. Instrumen penelitian berupa tes uraian yang diberikan saat pretest dan posttest. Analisis data menggunakan rumus uji t dua sampel. Sebelum data dianalisis, data terlebih dahulu diuji prasyarat analisis yaitu uji normalitas dan homogenitas. Kemudian dilakukan uji hipotesis berdasarkan data tersebut. Dari data penelitian diperoleh $t_{\text {hitung }} \geq t_{\text {tabel }}(13,62>1,98)$. Hasil penelitian menunjukan bahwa terdapat perbedaan efektivitas dalam penggunaan media pembelajaran berbasis video dengan pembelajaran konvensional terhadap pemahaman konsep matematis siswa
\end{abstract}

Kata Kunci : Media Video, Pembelajaran Konvensional, Pemahaman Konsep Matematis

\begin{abstract}
This research aims to know: whether there are effectiveness and the difference between using video based learning media and not using media with conventional learning reviewed from student mathematical concepts understanding. The kinds of this research is Quasi Experiments research with Pretest- Posttest Control Group Design. The population of this research are all student at SMPN 20 Batam in class VIII academic years 2016/2017. Taking sampling was done by Cluster Random Sampling technique. The research sample of experiment class is VIII.4 and sample of control class is VIII.2. The data was analyzed with using t test two sampling. Before the data was analyzed, the data was first tested on the pre requisite of analysis, there are normality test and homogeneity test. Then, conducted hypothesis test based on the data. From the research data obtained $t$ arithmetic $>t$ table (13. 62>1.98). The result of this research showed that there was the difference between video based learning media with conventional learning toward student mathematical concepts understanding. Keywords : by video, conventional learning, mathematical concepts understanding.
\end{abstract}

\section{Pendahuluan}

Menurut undang-undang RI No. 20 tahun 2003 tentang SISDIKNAS (Depdiknas, 2003) bahwa pendidikan adalah usaha sadar dan terencana untuk mewujudkan suasana belajar dan proses pembelajaran agar siswa secara aktif mengembangkan potensi dirinya untuk memiliki kekuatan dalam segala hal. Di dalam pendidikan matematika sendiri dapat dikatakan sebagai ilmu yang memiliki peranan yang sangat penting baik dalam bidanrg ilmu pengetahuan maupun ilmu teknologi. Menurut Chorida (Andy, 2017) bahwa matematika merupakan suatu bahasa. Matematika, suatu bahasa sangat diperlukan untuk dikomunikasikan baik secara lisan maupun tulisan sehingga informasi yang disampaikan dapat diketahui dengan baik oleh orang lain. Matematika menjadi salah satu mata pelajaran penentu kelulusan siswa pada jenjang pendidikan dasar dan menegah. Mata pelajaran matematika diberikan dari tingkat SD sampai 
Sekolah Tingkat Menengah Atas dan Perguruan Tinggi untuk membekali siswa dengan mengembangkan kemampuan menyampaikan informasi atau mengkomunikasikan gagasan antara lain melalui pembicaraan lisan, grafik, peta, diagram, dalam menjelaskan gagasan. Namun hingga kini kemampuan tersebut belum berkembang secara optimal.

Berdasarkan hasil observasi yang diperoleh pada kelas VIII.2 SMPN 20 Batam, bahwa proses pembelajaran yang dilakukan masih terpusat pada guru, sedangkan siswa cenderung hanya mendengar dan memperhatikan apa yang dijelaskan oleh guru dan siswa hanya menghafal rumus yang diberikan tanpa memahami konsep yang menjadi indikator keberhasilan pembelajaran. Selanjutnya jika mereka diberikan soal yang sedikit berbeda dari contoh soal yang diberikan, mereka akan cenderung mengalami kesulitan dan hanya dari beberapa siswa saja yang mampu untuk menjawab dengan benar.

Selain itu, siswa juga cenderung lupa akan materi yang telah dijelaskan pada pertemuan sebelumnya, padahal dalam materi yang sebelumnya dengan materi yang akan dipelajari selanjutnya mengalami keterkaitan satu dengan yang lainnya. Hal ini menunjukan bahwa masih rendahnya pemahaman konsep matematis dalam menyelesaikan soal pada materi persamaan garis lurus. Dapat dilihat dari hasil jawaban siswa dalam menyelesaikan soal persamaan garis lurus. Contohnya pada soal menentukan gradien dari suatu persamaan garis $2 \mathrm{y}=4 \mathrm{x}-10$, masih banyak siswa yang menjawab bahwa gradiennya adalah bernilai 4 . Padahal jelas bentuk umum persamaan suatu garis lurus adalah $y=m x+c$. secara otomatis bila kita memahami konsepnya, maka kita akan mengubah persamaan garis yang diketahui kedalam bentuk umum persamaan garis lurus. Sehingga penyelesaiannya menjadi:

$2 \mathrm{y}=4 \mathrm{x}-10$

$\mathrm{y}=\frac{4 x-10}{2}$

$y=2 x-5$, di dapat gradiennya adalah 2 .

Hal ini juga berdampak pada rendahnya kemampuan pemahaman konsep matematis siswa terlihat pada ulangan harian dimana masih banyak siswa mendapat nilai di bawah KKM yaitu 75, eperti yang terlihat pada tabel 1 berikut.

Tabel 1. Ketuntasan Hasil Ulangan Harian Siswa Kelas VIII SMP N 20 Batam

\begin{tabular}{lcccc}
\hline \multicolumn{1}{c}{ Kelas } & Rata-rata & Tuntas $(\%)$ & Tidak Tuntas $(\%)$ & KKM \\
\hline VIII.1 & 60,45 & 34 & 66 & \\
VIII.2 & 61,54 & 45 & 55 & \\
VIII.3 & 64,70 & 43 & 57 & 75 \\
VIII.4 & 68,47 & 59 & 41 & \\
VIII.5 & 68,80 & 67 & 33 & \\
VIII.6 & 68,34 & 61 & 63 & \\
VIII.7 & 62,61 & 37 & 48 & \\
VIII.8 & 64,97 & 52 & 62 & \\
VIII.Seni & 62,34 & 38 & 54 & \\
VIII.Olah- raga & 64,34 & 46 &
\end{tabular}

Sumber : Guru Pelajaran Matematika kelas VIII SMP Negeri 20 Batam. 
Berdasarkan tabel 1 di atas, dapat disimpulkan bahwa masih banyaknya siswa yang mendapat nilai dibawah KKM. Karena kurangnya pemahaman konsep siswa terhadap materi persamaan garis lurus. Guru sebagai tenaga pendidik dan juga sebagai fasilitator harus memiliki berbagai cara dan upaya agar siswa lebih mampu dalam memahami konsep matematis, sehingga dapat mencapai tujuan pembelajaran. Salah satunya dengan menggunakan media pembelajaran. Penggunaan media dalam pengajaran diutamakan untuk meningkatkan kualitas belajar, terutama dalam proses belajar agar siswa dapat memahami pelajaran matematika. Sejalan dengan pendapat, Yudhi Munadi (Bayu, 2017) adalah media yang mampu melibatkan banyak indera dan organ tubuh selama proses pembelajaran berlangsung. Jadi multimedia merupakan kumpulan atau kombinasi dari berbagai media berupa gambar, suara, gerak, video, animasi, dan teks yang bertujuan untuk mengkomunikasikan informasi.

Proses pembelajaran yang diterapkan dalam penelitian ini adalah media pembelajaran berbasis video. Menurut pendapat dari Cheppy Riyana (Rohman, 2013) media video pembelajaran adalah media atau alat bantu yang menyajikan audio dan visual yang berisi pesan-pesan pembelajaran baik yang berisi konsep, prinsip, prosedur, teori pengetahuan untuk membantu pemahaman terhadap materi suatu pembelajaran. Media video ini dapat menggantikan guru ketika para siswa ingin mengulang kembali materi yang telah dipelajari di sekolah kapanpun sesuai keinginan para siswa. Video pembelajaran ini berisikan materi serta penjelasan tentang bangun ruang sisi datar, dalam design yang lebih menarik. Video ini menggunakan aplikasi Video Scribe dan Wondershare Filmora. Aplikasi Video Scribe adalah software pembuat video elegan dengan menggunakan animasi tangan. Proses pembuatan video dengan menggunakan aplikasi ini pun cukup dibilang sangat mudah, karena kita hanya cukup dengan drag and drop gambar/tulisan yang ingin ditampilkan dan sedikit tambahan pengeditan untuk lebih memperindah tampilan. Aplikasi Wondershare Filmora digunakan untuk menambahkan suara pada video yang telah dibuat pada aplikasi Video Scribe, karena pada aplikasi ini lebih memiliki kualitas suara yang lebih baik dari Video Scribe.

Oleh sebab itu diharapkan dengan menggunakan video pembelajaran ini, siswa akan semakin mudah dalam memahami materi pembelajaran, sehingga proses pembelajaran menjadi lebih efektif. Hal ini juga bertujuan agar siswa mampu untuk mengerti dan memahami serta mengaplikasikan apa yang dipahami ke dalam kegiatan belajar. Jika siswa telah memiliki pemahaman yang baik, maka siswa akan siap untuk menjawab dari pertanyaan yang telah diberikan guru secara pasti.

\section{Metode Penelitian}

Jenis penelitian adalah eksperimen semu (quasi eksperimen). Penelitian eksperimen merupakan rangkaian aktivitas untuk memanipulasi variabel-variabel dalam sebuah penelitian dengan menjaga agar beberapa variabel yang lain tetap bernilai konstan (Wibisono, 2013). Dengan desain penelitian yang digunakan adalah "Pretest-Posttest Control Group Design". 
Tabel 2. Desain penelitian (Pretest-Posttest Control Group Design)

\begin{tabular}{cccc}
\hline Kelas & Tes Awal (Pretest) & Perlakuan & Tes Akhir \\
\hline Eksperimen & $\mathrm{T}_{1}$ & $\mathrm{X}$ & $\mathrm{T}_{3}$ \\
Kontrol & $\mathrm{T}_{2}$ & - & $\mathrm{T}_{4}$ \\
\hline
\end{tabular}

Sumber: (Wibisono, 2013)

Keterangan :

$\mathrm{X}$ : Pembelajaran matematika dengan menggunakan media pembelajaran berbasis video dan kelas

kontrol dengan pembelajaran konvensional tanpa diberi perlakuan

$\mathrm{T}_{1}$ : Pretes pada kelas eksperimen

$\mathrm{T}_{2}$ : Pretes pada kelas kontrol

$\mathrm{T}_{3}$ : Postes pada kelas eksperimen

$\mathrm{T}_{1}$ : Postes pada kelas kontrol

Populasi dalam penelitian ini adalah seluruh siswa kelas VIII SMPN 20 Batam sebanyak 10 kelas dengan jumlah siswa 432 orang. Pengambilan sampel pada penelitian ini adalah dengan teknik Cluster Random Sampling, yaitu teknik penentuan sampel yang digunakan apabila peneliti akan menggunakan kelompok intek (intact group), misalnya kelas disekolah (Lubis, 2013). Cluster Random Sampling dilakukan dengan cara pengocokan, diundi dengan menggunakan botol. Sampel pada penelitian ini adalah siswa kelas $\mathrm{VIII}_{2}$ dengan jumlah 44 siswa dan kelas $\mathrm{VIII}_{4}$. dengan jumlah 44 siswa.

Variabel bebas dalam penelitian ini adalah pembelajaran dengan menggunakan media video $\left(\mathrm{X}_{1}\right)$,dan kelas kontrol dengan menggunakan pembelajaran konvensional tanpa menggunakan media $\left(\mathrm{X}_{2}\right)$ dengan materi Bangun Ruang Sisi Datar. Variabel terikat dalam penelitian ini adalah pemahaman konsep matematis. Teknik pengumpulan data yang digunakan dalam penelitian ini menggunakan tes. Tes yang berisi soal esai yang mengandung indikator pemahaman konsep matematis materi bangun ruang sisi datar. Teknik analisis instrumen yang digunakan adalah validitas konstruk dengan korelasi Pearson Product Moment yang dikemukakan oleh Pearson (Arikunto, 2012). Sedangkan untuk menguji reliabilitas digunakan rumus Alpha Cronbach, tingkat kesukaran soal, daya beda soal. Teknik analisis data adalah normalitas menggunakan chi kuadrat, homogenitas dengan menggunakan uji-F dan uji hipotesis dengan menggunakan uji-t dua sampel.

\section{Hasil Penelitian dan Pembahasan}

Uji normalitas dan homogenitas sebelum perlakuan dapat disajikan dalam tabel 3 dan 4 berikut:

Tabel 3. Hasil Perhitungan Uji Normalitas Pre-test

\begin{tabular}{ccccc}
\hline No & Kelompok & $\boldsymbol{\chi}^{\mathbf{2}}{ }_{\text {hitung }}$ & $\boldsymbol{\chi}^{\mathbf{2}}$ tabel & Keterangan \\
\hline 1 & Eksperimen & 9,320 & 11,070 & Normal \\
2 & Kontrol & 7,860 & 11,070 & Normal \\
\hline
\end{tabular}

Karena pada kelas kelompok eksperimen dengan penggunaan media pembelajaran berbasis video dan kontrol, $\chi^{2}{ }_{\text {hitung }}<\chi^{2}$ tabel dapat disimpulkan kedua sampel tersebut berasal dari populasi normal. 
Tabel 4. Hasil Perhitungan Homogenitas Pretes

\begin{tabular}{cccccc}
\hline No & Kelompok & Varians $\left(\boldsymbol{S}^{\mathbf{2}}\right)$ & $\boldsymbol{F}_{\text {hitung }}$ & $\boldsymbol{F}_{\text {tabel }}$ & Keterangan \\
\hline 1 & Eksperimen & 170,50 & & & \\
2 & Kontrol & 152,95 & 1,114 & 1,6607 & Homogen \\
\hline
\end{tabular}

Karena $F_{\text {hitung }}<F_{\text {tabel }}$, maka dapat disimpulkan bahwa variansi dari kedua kelompok homongen (sama).

Uji Normalitas setelah perlakuan

Tabel 5. Hasil Perhitungan Uji Normalitas

\begin{tabular}{cccccc}
\hline No & Kelompok & $\mathbf{N}$ & $\chi^{2}{ }_{\text {hitung }}$ & $\chi^{2}{ }_{\text {tabel }}$ & $\begin{array}{c}\text { Keteranga } \\
\mathbf{n}\end{array}$ \\
\hline 1 & Eksperimen & 44 & 8,24 & & Normal \\
2 & Kontrol & 44 & 8,48 & 11,070 & Normal \\
\hline
\end{tabular}

Berdasarkan tabel di atas terlihat bahwa $\chi_{\text {hitung }}^{2}<\chi_{\text {tabel }}^{2}$ maka kedua kelompok tersebut berasal dari data dengan populasi normal.

Uji homongenitas setelah perlakuan

Tabel 6. Hasil Perhitungan Homogenitas

\begin{tabular}{cccccc}
\hline No & Kelompok & $\boldsymbol{S}^{\mathbf{2}}$ & $\boldsymbol{F}_{\text {hitung }}$ & $\boldsymbol{F}_{\text {tabel }}$ & Keterangan \\
\hline 1 & Eksperimen & 39,99 & & & \\
2 & Kontrol & 38,22 & 1,046 & 1,6607 & Homogen
\end{tabular}

Berdasarkan tabel di atas, karena $F_{\text {hitung }}<F_{\text {tabel }}$, maka dapat disimpulkan bahwa variansi dari kedua kelas dinyatakan homongen (sama).

Hasil Uji t dua sampel dengan (Separated Varians)

Berdasarkan data posttest pemahaman matematis siswa pada kelas eksperimen dan kelas kontrol diperoleh nilai $t_{\text {hitung }}$ untuk kelas eksperimen dan kelas kontrol setelah dianalisis menggunakan rumus uji $\mathrm{t}$ dua sampel (separated varians) sebesar 13,62 dan $t_{\text {tabel }}$ sebesar 1,988 , dapat disimpulkan bahwa $t_{\text {hitung }}>t_{\text {tabel }}(13,62>1,988)$ maka $H_{a}$ diterima artinya terdapat perbedaan efektivitas antara pembelajaran media berbasis video dengan pembelajaran konvensional terhadap pemahaman konsep matematis siswa kelas VIII SMPN 20 Batam Tahun Pelajaran 2016/2017 pada materi bangun ruang sisi datar. Pembelajaran dengan menggunakan media video dapat dikatakan efektif dari pada pembelajaran tanpa mengggunakan media dilihat dari hasil posttest pemahaman konsep matematis yang menunjukan bahwa nilai rata-rata kelas eksperimen lebih tinggi dari kelas kontrol.

Hasil penelitian ini juga menunjukkan bahwa pembelajaran dengan penggunaan media video ini lebih membantu guru dan siswa dalam proses pembelajaran di kelas. Karena melalui media video ini bisa menampilkan animasi yang menarik yang sesuai dengan isi materi 
pembelajaran, sehingga bisa membantu siswa dalam pemahaman konsep matematis dan membantu guru dalam mencapai tujuan pembelajaran di kelas.

Berikut ditampilkan beberapa penampilan video pembelajaran pada saat proses penelitian yang dilakukan di SMPN 20 Batam:
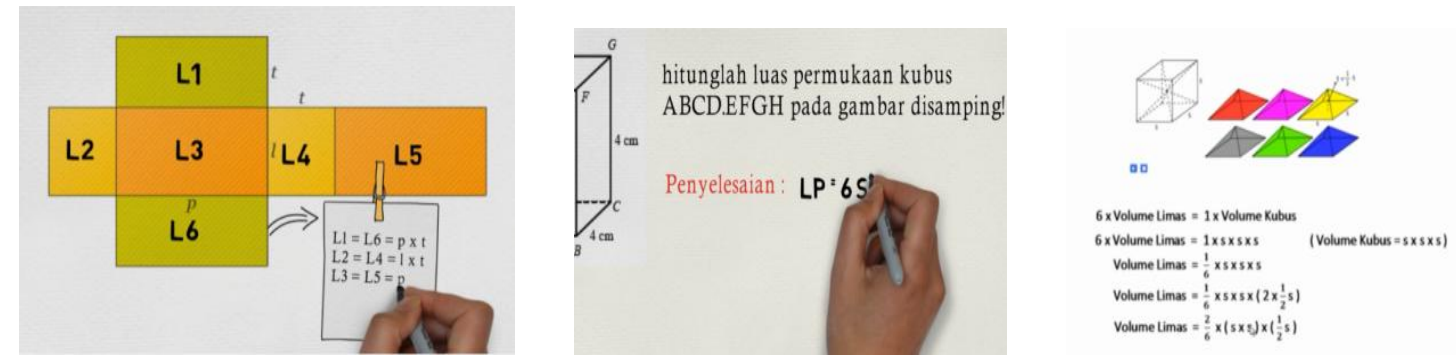

Gambar 1. Skema video pembelajaran

Penggunaan media pembelajaran berbasis video ini juga memiliki beberapa keuntungan yaitu, siswa kelompok eksperimen menyukai proses belajar, mereka juga lebih paham terhadap materi yang di sampaikan. Hal ini sejalan dengan penelitian yang dilakukan oleh (Abdullah, 2013) menyimpulkan bahwa penggunaan media pembelajaran dalam pembelajaran matematika dapat meningkatkan pemahaman konsep dan prestasi belajar matematika.

\section{Kesimpulan dan Saran}

Kesimpulan dalam penelitian ini terdapat perbedaan efektivitas dalam penggunaan media pembelajaran dengan berbasis video dan tidak menggunakan media pada pembelajaran konvensional terhadap pemahaman konsep matematis siswa kelas VIII SMPN 20 Batam. Pembelajaran dengan menggunakan media video dapat dikatakan efektif dari pada pembelajaran tanpa mengggunakan media dilihat dari hasil posttest pemahaman konsep matematis yang menunjukan bahwa nilai rata-rata kelas eksperimen lebih tinggi dari kelas kontrol. Dan saran pada penelitian ini agar penelitian lanjutan dapat meneruskan dan mengembangkan penelitian untuk variabel lainnya dalam meningkatkan pemahaman konsep matematis siswa.

\section{Daftar Pustaka}

Abdullah, B. M. (2013). Peningkatan Pemahaman Konsep dan Prestasi Belajar Matematika Menggunakan Media Adobe Flash SiswaKelas VIII Semester Genap SMP Negeri 2 Wuryantoro Tahun Ajaran 2012/2013. Universitas Muhammadiyah Surakarta.

Andy, sapta. (2017). Pengaruh Model Pembelajaran Experiential Learning Terhadap Komunikasi Matematis siswa. Pythagoras, IV(2), 94-99.

Arikunto, S. (2012). Dasar-Dasar Evaluasi Pendidikan. Jakarta: Bumi Aksara.

Bayu, S. (2017). Pengembangan Multimedia Pembelajaran untuk Memfasilitasi Kemampuan Pemahaman Konsep Matematis. Pythagoras, VI(1), 85-93.

Depdiknas. (2003). Undang-undang RI Nomor 20 Tahun 2003, Tentang Sistem Pendidikan Nasional. 
Lubis, S. (2013). Metodologi Penelitiaan Pendidikan. Padang: Sukabina Press.

Rohman, M. dan S. A. (2013). Strategi dan Desain Pengembangan Sistem Pembelajaran. Jakarta: Prestasi Pustaka Publisher.

Wibisono, D. (2013). Panduan Menyusun Skripsi, Tesis, dan Disertasi. Yogyakarta: Penerbit Andi. 